International Journal of Current Advanced Research

ISSN: O: 2319-6475, ISSN: P: 2319 - 6505, Impact Factor: SJIF: 5.995

Available Online at www.journalijcar.org

Volume 6; Issue 5; May 2017; Page No. 3964-3967

DOI: http://dx.doi.org/10.24327/ijcar.2017.3967.0407

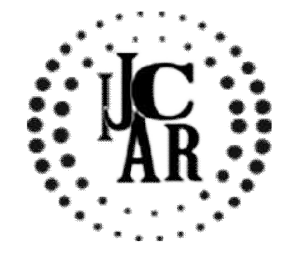

Research Article

\title{
EVALUATION OF RETINAL NERVE FIBER LAYER THICKNESS AND OPTIC NERVE HEAD PARAMETER IN MIGRAINE AS A RISK FACTOR IN OPEN ANGLE GLAUCOMA
}

\author{
Masitha Dewi Sari*., Aryani A Amra and Vanda Virgayanti
}

Department of Opthalmology, Medical Faculty Sumatera Utara University

Medan, Indonesia

\section{A R T I C L E I N F O}

Article History:

Received $20^{\text {th }}$ February, 2017

Received in revised form $10^{\text {th }}$ March, 2017

Accepted $8^{\text {th }}$ April, 2017

Published online $28^{\text {th }}$ May, 2017

\section{Key words:}

Migraine, Retinal Nerve Fiber Layer, Optical Coherence Tomography

\begin{abstract}
A B S T R A C T
Background: Migraine is a primary debilitating headache disorder with common neurolological signs. Variations in optic nerve perfusions quality or retinal microcirculation may end up in ganglion cell damage in patients with migraine

Methods: A prospective, analytical observational with cross sectional study was conducted at the Adam Malik Hospital from January 2016 to July 2016 after approved by the Ethics Committee for Health Research Sumatera Utara University School of MedicineThirty seven patients diagnosed with migraine divided two groups as migraine without aura and migraine with aura were evaluated. Retinal nerve fiber layer (RNFL) thickness and Optc Nerve Head (ONH) was measured by using Cirrus Optical Coherence Tomography (OCT)

Results: RNFL became thinner and ONH became enlargement in several patients with migraine but not significantly differences in all quadrant between the two groups. There was significantly differences the risk of open angle glaucoma between the two groups, wheres seven migraine without aura patients and ten migraine with aura patients got normal tension glaucoma $(\mathrm{NTG})(\mathrm{p}<0,05)$.

Conclusion: Normal Tension Glaucoma (NTG) is a risk factor in migraine and the retinal blood flow decreased theory might be able to defend
\end{abstract}

Copyright $₫ 2017$ Masitha Dewi Sari et al. This is an open access article distributed under the Creative Commons Attribution License, which permits unrestricted use, distribution, and reproduction in any medium, provided the original work is properly cited.

\section{INTRODUCTION}

Migraine is a primary debilitating headache disorder affecting $10 \%$ to $15 \%$ of people world. ${ }^{1}$ Migraine is the most common cause of recurrent moderate to severe headache. Acording to a survey, the lifetime prevalence of this syndrome is $43 \%$ for women and $18 \%$ for men. ${ }^{2}$ Migraine symptom typically last 4 to 72 hours and this form of headache can be quite debilitating. The pathofisiology of migraine is complex. ${ }^{3}$ There are two types of migraine: migraine with aura and migraine without aura. Migraine with aura is characterized by temporary symptoms known as the "aura" which typically develop prior to a migraine attack. An aura may occur before or during the head pain from a migraine attack. Migraine without aura usually called"common migraine". A migraine without aura is the most common type of migraine headache. It doesn't have the early symptoms. ${ }^{4}$ Physicians have largely discarded the vascular hypothesis, which was based on findings of changes in blood flow during migraine attack and the efficacy of some vasoactive substance in treating migraine system. ${ }^{5}$ Initial interest in a migraine-glaucoma connection stemmed from the earlier theory of migraine as a primarily vascular disease. Epidemiological data show that an increased

*Corresponding author: Masitha Dewi Sari

Department of Opthalmology, Medical Faculty Sumatera Utara University Medan, Indonesia prevalence of migraine in patients with glaucoma, particularly in patients with normal tension glaucoma (NTG). Furthermore, the headache in migraine patients might mimic acute angle closure glaucoma attack, whish is an important problem in differential diagnosis. Glaucoma comprises a set of ocular disorders that lead to optic nerve damage that is often associated with increased intraocular pressure, which is the leading cause of irreversible blindness worldwide. The risk ratio for migraine in Collaborative Normal Tension Glaucoma Study (CNTGS) was 2, 58 and for the female gender 1, 85. But from The Blue Mountain Eye Study found no relationship between open angle glaucoma and migraine, but reported a significant odds ratio of 2,5 for glaucoma in people aged 70 to 79 who had a history of migraines. The investigators felt that migraine might be a "surrogate for vasospam or vascular disregulation"., 6,7 In view of these observations, the aim of this current study to evaluate the retinal nerve fiber layer thickness (RNFL) and Optic Nerve Head $(\mathrm{ONH})$ in migraine as a risk factor in open angle glaucoma.

\section{MATERIALS AND METHODS}

\section{Subjects}

This was a prospective, cross sectional study comprising thirty seven patients patients with migraine divided into two 
groups: migraine without aura patients and migraine with aura patients. The migraine patients referred from Neurologic department. These subjects were recruited consecutively at Haji Adam Malik Hospital North Sumatera, Indonesia. Ethical approval was obtained from University Sumatera Utara Ethics Committee. A written consent was obtained from all patients by the researchers.

All subjects underwent ophthalmologic examination included measured of best corrected visual acuity (BCVA), intraocular pressure by Goldman applanation tonometry and slitlamp examination, gonioscopic (Carl Zeiss Meditec AG, Jenna, Germany), visual field with Octopus 301 and reliable SAP, optic disc with direct funduscopy (Neitz, Japan).

Inclusion criteria: We included patients who fulfilled the following criteria: migraine patients, age $>18$ years old, an open iridocorneal angle. Exclusion criteria: The exception criteria included patient with ocular infection, taking medication as steroid and secondary glaucoma.

\section{Retinal Nerve Fiber Layer and Optic Disc Analyses}

All patients had their RNFL measured by Cirrus HD- OCT (Carl Zeiss, Meditec, Dublin, CA). Cirrus HD-OCT (Carl ZeisssMeditec) improves on time-domain systems, allowing performance of up 27000 axial scans per second. Cirrus HDOCT imaging, the Macular Cube 200 x 200 Combo protocol was used. The protocol consists of two perpendicular line scans centered at the fovea followed by a cube scan also centered at the fovea.The line scans were $6 \mathrm{~mm}$ in the transverse direction, had a $2 \mathrm{~mm}$ acial depth, and was composed of $200 \times 200$ axial scans. The Cirrus RNFL map represents a $6 \times 6 \mathrm{~mm}$ cube of A-scan data centered over the optic nerve in which a $3.4 \mathrm{~mm}$ diameter circle RNFL data is extracted to create what is refered. It to as the TSNIT map (temporal, superior, nasal, inferior) is displayed as a false color scale with the thickness values by quadrants and clock hours, and the RNFL peaks give a sense of the anatomic distribution of nerve fiber axons represented by the superior and inferior bundles that emanate from optic neve. SD OCT had a sensitivity of $83 \%$ and a specificity of $88 \%{ }^{9,10}$

Cirrus HD-OCT also automatically outlines the optic nerve head, optic cup, and disc borders similar to mental estimations by clinicians, but then also calculates more objective measurements such as optic disc area and neuroretinal rim area in addition to the classic clinician subjective average. And vertical cup to disc ratio. This allows the 3, $4 \mathrm{~mm}$ RNFL circle to always be centered in the same spot within the cube. $\mathrm{ONH}$ parameters have also been found to have excellent ability to discriminate between normal eyes and eyes with even mild glaucoma. The parameters found to have the greatest diagnostic capability are vertical rim thickness, rim area, and vertical cup to disc ratio. These $\mathrm{ONH}$ parameters were found to be as good as RNFL thickness parameters in diagnosing glaucoma. ${ }^{11}$

\section{Statistical Analysis}

The collected data write in the research publication and keep in the computer. The collected data keeped in computer analysed by using the statical software. To analyse between migraine and open angle glaucoma, chi square or Fischer Exact test was used. Statistical analyses were performed with SPSS 19, 0 and the level significance was $\mathrm{P}<0,05$ in all statistical test.

\section{RESULT}

The study was conducted from January 2016 to July 2016 in thirty seven patients with migraine.

Table 1The demographic parameters from 37 migraine patients

\begin{tabular}{|c|c|c|c|c|c|}
\hline & $\begin{array}{r}\text { Migrain } \\
\text { Aura }\end{array}$ & $\begin{array}{l}\text { without } \\
n=21)\end{array}$ & $\begin{array}{l}\text { Migr: } \\
\text { Aura }\end{array}$ & $\begin{array}{l}\text { with } \\
=16 \text { ) }\end{array}$ & \\
\hline Variable & Total & $\%$ & Total & $\%$ & $\mathrm{p}$ \\
\hline Age & & & & & 0.426 \\
\hline $18-39$ y.o & 10 & 27 & 9 & 23.4 & \\
\hline $40-61$ y.o & 11 & 29.7 & 7 & 18.9 & \\
\hline Sex & & & & & 0.429 \\
\hline Male & 7 & 18.9 & 4 & 10.8 & \\
\hline Female & 14 & 37.8 & 12 & 32.4 & \\
\hline Duration of migraine & & & & & 0.222 \\
\hline$\leq 1$ year & 13 & 35.1 & 7 & 18.9 & \\
\hline$>1$ year & 8 & 21.6 & 9 & 24.3 & \\
\hline
\end{tabular}

Based on the above table appear there was no significant difference from the demographic data $(\mathrm{P}>0,05)$.

Table 2 Distribution of Retinal Nerve Fiber Layer Thickness (RNFL) Superior, Inferior, Nasal, Temporal and Average Thickness in Migraine Patients

\begin{tabular}{|c|c|c|c|c|c|}
\hline & $\begin{array}{r}\text { Mig } \\
\text { witho } \\
\text { (n }\end{array}$ & $\begin{array}{l}\text { ne } \\
\text { dura } \\
\text { ) }\end{array}$ & $\begin{array}{l}\text { Migre } \\
\text { Aura }\end{array}$ & $\begin{array}{l}\text { with } \\
n=16 \text { ) }\end{array}$ & \\
\hline RNFL & Total & $\%$ & Total & $\%$ & $\mathrm{p}$ \\
\hline Superior & & & & & 0.429 \\
\hline Normal $(\geq 99,5)$ & 20 & 54,1 & 10 & 27 & \\
\hline Thinner $(<99.5)$ & 1 & 2,7 & 6 & 16,2 & \\
\hline Inferior & & & & & 0.206 \\
\hline Normal $(\geq 99,5)$ & 20 & 54.1 & 13 & 35.1 & \\
\hline Thinner $(<99.5)$ & 1 & 2.7 & 3 & 8.1 & \\
\hline Nasal & & & & & 0.413 \\
\hline Normal ( $\geq 56)$ & 19 & 48,6 & 15 & 40,5 & \\
\hline Thinner $(<56)$ & 2 & 8,1 & 1 & 2,7 & \\
\hline Temporal & & & & & 0.633 \\
\hline Normal $(\geq 52,5)$ & 18 & 48.6 & 14 & 37.8 & \\
\hline Thinner $(<52.5)$ & 3 & 8.1 & 2 & 5.4 & \\
\hline Average Thickness & & & & & 0.568 \\
\hline Normal $(\geq 80)$ & 20 & 54.1 & 16 & 43.2 & \\
\hline Thinner $(<80)$ & 1 & 2.7 & 0 & 0 & \\
\hline
\end{tabular}

From the table 2, there was no significantly differences from the superior, inferior, nasal, temporal and average thickness RNFL between migraine without aura and migraine with aura $(\mathrm{p}>0,05)$.

Table 3 Distribution of Optic Nerve Head (C/D Horizontal Ratio, C/D Vertical Ratio and C/D Area Ratio)

\begin{tabular}{cccccc}
\hline & $\begin{array}{c}\text { Migren without } \\
\text { Aura }(\mathbf{n = 2 1})\end{array}$ & $\begin{array}{c}\text { Migren with } \\
\text { Aura } \\
(\mathbf{n = 1 6})\end{array}$ & \\
\hline Optic Nerve Head & Total & $\%$ & Total & $\%$ & $\mathrm{p}$ \\
& & & & & 0.685 \\
C/D Horizontal Ratio & & & & & \\
Normal $\quad(\leq 0,830)$ & 20 & 54.1 & 15 & 40.5 & \\
Enlarge (>0.830) & 1 & 2.7 & 1 & 2.7 & \\
C/D Vertical Ratio & & & & & 0.317 \\
Normal $(\leq 0,611)$ & 17 & 45.9 & 11 & 29.7 & \\
Enlarge (>0.611) & 4 & 10.8 & 5 & 13.5 & \\
C/D Area Ratio & & & & & 0.685 \\
Normal $(\leq 0,650)$ & 20 & 54.1 & 15 & 40.5 & \\
Enlarge $(>0.650)$ & 1 & 2.7 & 1 & 2.7 & \\
\hline
\end{tabular}

From the table 3 , there was no significantly differences from the optic nerve head (C/D Horizontal Ratio, C/D Vertical Ratio, C/D Area Ratio) between migraine without aura and migraine with aura $(p>0,05)$. 
Table 4 Distributions from intra ocular pressure and risk for open angle glaucoma

\begin{tabular}{|c|c|c|c|c|c|}
\hline \multirow{3}{*}{$\begin{array}{c}\text { Variable } \\
\text { Intra Ocular Pressure (IOP) } \\
(\mathrm{mmHg})\end{array}$} & \multicolumn{2}{|c|}{$\begin{array}{c}\text { Migren without } \\
\text { Aura } \\
(\mathrm{n}=21)\end{array}$} & \multicolumn{2}{|c|}{$\begin{array}{l}\text { Migren with } \\
\text { Aura }(n=16)\end{array}$} & \multirow{3}{*}{$\begin{array}{c}\mathrm{P} \\
0.1000\end{array}$} \\
\hline & Total & $\%$ & Total & $\%$ & \\
\hline & & & & & \\
\hline Normal ( 10-21) & 20 & 54.1 & 15 & 40.5 & \\
\hline Higher $(>21)$ & 1 & 2.7 & 1 & 2,7 & \\
\hline $\begin{array}{l}\text { Open Angle Glaucoma } \\
\text { Primary Open }\end{array}$ & & & & & $0.045 *$ \\
\hline $\begin{array}{l}\text { Angle Glaucoma } \\
\text { (POAG) }\end{array}$ & 1 & 2,7 & 1 & 2,7 & \\
\hline $\begin{array}{l}\text { Normal Tension } \\
\text { Glaucoma (NTG) }\end{array}$ & 7 & 18.9 & 10 & 27.0 & \\
\hline Suspect Glaucoma & 1 & 2,7 & 1 & 2,7 & \\
\hline Without Glaucoma & 12 & 32,4 & 4 & 10,8 & \\
\hline
\end{tabular}

From the table 4 , there was significantly differences the risk of open angle glaucoma between the two groups, wheres seven migraine without aura patients and 10 migraine with aura patients got normal tension glaucoma (NTG) $(\mathrm{p}<0,05)$.

\section{DISCUSSION}

Potential pathological link between migraine and glaucoma has been proposed. Migraine is a disorder of the central nervous system, with both neural and vascular involvement. $^{12,13}$ Vascular factors have been well noted to play an important role in the pathophysiology of glaucoma. Among the glaucoma types, NTG, a subtype of open angle glaucoma is associated with retinal vascular dysregulation and poor blood flow over the optic nerve head. The common vasospastic mechanism between NTG and migraine has been proposed. However contradictory reported was still noted. $^{14,15,16}$

Based on result examination, there was changing of retinal nerve fiber layer thickness (RNFL) wheres in several patients RNFL became thinner but there was no significant differences of Retinal Nerve Fiber Layer Thickness (RNFL) superior, inferior, nasal, temporal and average thickness between migraine without aura and migraine with aura patients (Table 2). The changing of RNFL in several patients caused of the ischemic factor due to hipoperfusion to optic nerve head and the damage of ganglion retinal cell and retinal nerve fiber layer thickness. Sorkhabi R et al reported RNFL thickness was only significantly thinner in nasal quadrant in migraineurs compared to control groups. ${ }^{17,18}$

There was no significant differences of Optic Nerve Head between migraine without aura and migraine with aura patients (Table 3). This result correlated with the several studies reported no significant differences of the optic nerve head parameters in migraine patients. ${ }^{18}$

From the risk factor of open angle glaucoma, there was a significant differences in migraine without aura and migraine with aura patients, whereas normal tension glaucoma (NTG) as a risk factor in migraine $(\mathrm{p}<0,05)$. This result suitable with Collaborative Normal Tension Glaucoma Study (CNTGS) that the risk factor for migraine was 2,58 and The Blue Mountain Eye Study reported a significant odds ratio of 2,5 for glaucoma in people aged 70 to 79 who had a history of migraines. $^{19,20,21}$
In conclusion, although migraine is a common, sometimes debilitating conditions, its particular role in glaucoma is unclear. Only identifiable risk factor for normal tension glaucoma in migraines. However, clinicians should still consider the potential risk of glaucoma in certain high-risk groups. In the light of our findings and the evidence from previous reports, we propose that migraine is a risk factor for normal tension glaucoma. But further studies are needed to prospective longitudinal clinical trials on larger populations and longer times to conclude the exact role of mechanism the risk factor for normal tension in migraine and risk factor another type of glaucoma in migraine.

\section{Acknowledgment}

The authors are deeply indebted to Faculty of Medicine University of Sumatera Utara for providing equipment and scientific apparatus

\section{Conflict of Interest}

The authors declare that there are no conflicts of interest

\section{References}

1. Stovner L, Hagen K, Jensen R, et al. The global burden of headache: a documentation of headache prevalence and disability worldwide. Cephalgia 2007; 27: 193-210

2. Stewart W, Wood C, Reed M, et al. Cumulative lifetime migraine incidence in women and men. [published online ahead of print July 15,2008].Cephalgia

3. Stewart WF, Linet MS, Celentano DD, et al. Age-and sex-spesific rates of migraine with and without visual aura. Am J Epidemiol. 2001; 134:1111-1120

4. Friedman DI, Gordon LK, Quiros PA.Headache attributable to disorders of the eye. Curr Pain Headache Rep .2010;14:62-72

5. Lauritzen M, Olsen TS, Larsen NA, Paulson OB. Changes in the regional cerebral blood flow during the course of classic migraine attacks. Ann Neurol. 2003;13(6):633-641

6. Nesher R, Mimouni MD, Khoury S, et al. Delayed diagnosis of sub acute angle closure glaucoma in patients presenting with headache. Acta Neurol Belg. 2014; 114: 269-272

7. Freeman EE, Munoz B, West SK, Jampel HD, friedman DS. Glaucoma and quality of life: the Salisbury eye evaluation. Ophthalmology. 2008; 115: 233-8

8. Gupta S, Mehrotra S, Villalon CM, Perusquia M, Saxena PR, Van Den Brik AM. Potential role of female sex hormones in the pathology of migraine. Pharmacology and Therapeutics. 2007; 113: 321- 340

9. Leung CK, Yu M, Weinreb RN. Retinal Nerve Fiber Layer Imaging with Spectral- Domain Optical Coherence Tomography, Patterns of Retinal Nerve Fiber Layer Progression, Ophthalmology. 2012;119: 1858-1866

10. Leite MT, Rao HL, Weinreb RN, Agreement among Spectral-Domain Optical Coherence Tomography Instruments For Assessing Retnal Nerve Fiber Layer Thickness. Am JOpthalmol 2011, 151: 85-92

11. Mwanza JC, Chang RT, Budenz DL, Reproducibility of Peripapillary Retinal Nerve Fiber Layer Thickness 
and Optic Nerve Head Parameters Measured with Cirrus HD-OCT in Glaucomatous Eye. Invest Ophthalmol Vis Sci, 2010; 51: 5724-5730

12. Charles AC, Baca SM. Cortical spreading depression and migraine. Nat rev Neurol. 2013;9:637-644

13. Pietrobon D, Moskowitz MA. Pathophysiology of migraine. Annu Rev Physiol 2013;75:365-391

14. Flammer J, Orgul S, Costa VP, et al. The impact of ocular blood flow in glaucoma. Prog Retin Eye Res 2002; 21:359-393

15. Broadway DC, Drance SM. Glaucoma and vasospasm. Br J Ophthalmol 1998; 82:862-870

16. Flammer J, Konieczka K, Flammer AJ. The primary vascular dysregulation syndrome: implications for eye diseases. EPMA J 2013; 4:14
17. Sorkhabi R, Moastafaei S, Ahoor M, Talebi M. Evaluation of retinal nerve fiber thickness in migraine. Iran J Neurol. 2013; 12(2):51-55

18. Hatice Nur Colak et al. Retinal nerve fiber layer, ganglion cell complex, and choroidal thicknesses in migraine. Arq.Bras.Oftalmol. 2016; 79(2): 165-170

19. Usui T, Iwaa K, Shirakashi M, et al. Prevalence migraine in low tension glaucoma and primary open angle glaucoma in Japanese. Br J Ophthalmol. 2001; 75:224-226

20. Lin $\mathrm{HC}$, Chien $\mathrm{CW}, \mathrm{Hu} \mathrm{CC}$, et al. Comparison of comorbid conditions between open angle glaucoma patients and a control cohort: a case-control study. Ophthalmology 2010; 117-2088-2095

21. Wang JJ, Mitchell P, Smith W. Is there an association between migraine headache and open angle glaucoma? Findings from the Blue Mountain Eye Study. Ophthalmology. 1997; 104:1714-1719

\section{How to cite this article:}

Masitha Dewi Sari et al (2017) 'Evaluation Of Retinal Nerve Fiber Layer Thickness And Optic Nerve Head Parameter In Migraine As A Risk Factor In Open Angle Glaucoma', International Journal of Current Advanced Research, 06(05), pp. 3964-3967. DOI: http://dx.doi.org/10.24327/ijcar.2017.3964-3967.0407 